\title{
The right not to know: the case of psychiatric disorders
}

\author{
Lisa Bortolotti, Heather Widdows
}

Philosophy Department, University of Birmingham, Edgbaston, UK

\section{Correspondence to} Lisa Bortolotti, Philosophy Department, University of Birmingham, Edgbaston, Birmingham B15 2TT, UK; I.bortolotti@bham.ac.uk

Received 5 November 2010 Revised 4 April 2011 Accepted 27 April 2011 Published Online First 9 June 2011

\section{(2) UNLOCK:}

This paper is freely available online under the BMJ Journals unlocked scheme, see http:// jme.bmj.com/site/about/ unlocked.xhtml

\section{ABSTRACT}

This paper will consider the right not to know in the context of psychiatric disorders. It will outline the arguments for and against acquiring knowledge about the results of genetic testing for conditions such as breast cancer and Huntington's disease, and examine whether similar considerations apply to disclosing to clients the results of genetic testing for psychiatric disorders such as depression and Alzheimer's disease. The right not to know will also be examined in the context of the diagnosis of psychiatric disorders that are associated with stigma or for which there is no effective treatment.

\section{INTRODUCTION}

The ethical literature on the right not to know has focused on the nature of genetic information and its implications for autonomy, and on the competing interests of family members when one member of the family wishes to know the result of genetic testing but others do not. In this paper, we shall consider arguments for the right not to know in the context of predictive genetic testing and diagnosis, especially with respect to chronic diseases (eg, schizophrenia), degenerative conditions (eg, dementia) or disorders for which there is no effective treatment (eg, psychopathy). A person who learns to be at high risk of developing a disorder that is stigmatised and associated with a lifetime of struggle can suffer psychological harm or discrimination. A person who is diagnosed with such a disorder can lose hope and self-esteem and thus compromise the successful management of his or her symptoms. However, potential benefits of genetic and diagnostic information and marked differences in people's preferences and interests suggest that there isn't a 'right' not to know in psychiatry.

\section{GENETIC TESTING AND THE RIGHT NOT TO KNOW: ARGUMENTS FOR AND AGAINST}

Those who argue against the right not to know in the context of genetic testing believe that knowing one's genetic status is an important aim in itself; this is summed up by the phrase 'knowledge is power.' They argue instead that there might be a right or even a duty to know, or a duty to tell or to warn other family members. ${ }^{1}$ A duty to pass on the information implies that knowing is in the best interests of those who are told. A number of possible reasons are given for this claim.

When we say, 'knowledge is power', we mean that having knowledge is better than being in a state of uncertainty. Underlying this claim is the conviction that the more knowledge one has, the more informed and effective decisions one can make. Refusing to acquire knowledge about one self is deemed by some to abdicate one's duty to make informed and reasonable autonomous decisions about one's own life-and conversely that the right not to know lacks justification. ${ }^{2}{ }^{3}$ This presumes a model of autonomy in which autonomy is protected if the individual makes a choice based on as much and as accurate information as possible; Husted, discussing this issue, refers to it as a 'thin conception of autonomy'.

Choosing not to know is regarded as an ethical problem and as a practical problem, as it arguably limits the capacity to plan for the future and manage future symptoms. Even if there is no treatment or cure, this does not mean that there are no lifestyle changes or choices that follow from knowing whether or not one will (in the case of a dominant gene disorder such as Huntington's disease (HD)) or is likely to (if one tests positive for BRCA1 or BRCA2) develop a particular illness, for instance, choices concerning one's employment, reproduction and financial situation.

Finally, choosing not to know may impact negatively on the interests of third parties: reproductive decisions may not be well informed, and family members may be prevented from making their own testing and lifestyle decisions. Preventing others from having access to this information is deemed so important that some have argued that individuals should not be able to keep the results of genetic tests private, but should share information with family. Accordingly, family models, rather than the usual practices of individual consent and confidentiality, have been suggested to manage genetic testing within families: for instance, the 'joint account' model and the 'family covenant'. 56

Set against these arguments are competing claims about the right not to know; these can be summed up by the phrase 'ignorance is bliss.' The idea is that knowing does not in fact add to the quality of life, but reduces it. For instance, even while still in good health, one might behave or be treated by others as if one were already ill, and thus become the 'worried well', extending the definition of illness beyond those who feel ill and exhibit symptoms to those who are at risk.

While those who argue for the right to know argue that knowledge is necessary for autonomy, their opponents argue that autonomy is precisely what grounds the right not to know. ${ }^{7}$ The idea is that one's autonomy might be protected by one's refusal to obtain genetic information because one is ensured an 'open future'. ${ }^{8}$ The idea is that knowing the probability of developing a certain disorder in 
the future compromises one's quality of life and conditions one's choices. That an 'open future' is something that some individuals value is confirmed by the lower-than-expected uptake of the test for $\mathrm{HD}$. For instance, "prior to the availability of a predictive test of $\mathrm{HD}, 57-84 \%$ of at-risk individuals indicated an interest in the test' ( $p$ 463), ${ }^{9}$ but in fact uptake of the test is less than $20 \%$. 10 Those who argue that the right not to know is compatible with and grounded by autonomy deploy what Husted calls a 'thick conception of autonomy'-autonomy understood as an activity of 'self-creation' ( $p$ 61). ${ }^{4}$

A further consideration in support of the right not to know is that if there is no treatment available or preventive measures that can be taken, the benefits of knowing are outweighed by the harms of knowing; these may include stigma, discrimination in employment and psychological harm. The psychological effects of genetic diagnosis are not clear, and there is no consensus about what is most beneficial in terms of psychological well-being. However, some research has been done on people who are told that they may develop a disease such as breast cancer or HD. Predictably, people whose tests are positive tend to experience more distress than people whose tests are negative, but distress usually remains in the normal range, and does not lead to either suicide or high levels of anxiety or depression. When levels of anxiety increase, they return to normal in a relatively short time. ${ }^{11} 12$ One exception is constituted by people who learn that they will not develop a certain disease, but members of their family have or are likely to develop the same disease. Symptoms of anxiety and depression are observed in this case, as a form of 'survivor guilt'. It is of course open to those who expect to experience negative effects, such as feeling depressed or suicidal, not to take the test. ${ }^{13}$ Interestingly, for some people, knowing (even in case of positive results) is less distressing than living in uncertainty. For others, uncertainty is preferable, and the exceptionally low uptake of the HD test is particularly significant in this respect.

\section{RISKS AND BENEFITS OF GENETIC TESTING FOR SOME PSYCHIATRIC DISORDERS}

Can the arguments above apply to psychiatry? Not many psychiatric disorders have known genetic bases-for instance, the bases for dementia and autism are better known than those for schizophrenia, depression and bipolar disorder. As Laegsgaard et $a l^{14}$ say, "the aetiology of mental illnesses has shown to be polygenic and multifactorial, complicating both the research seeking to identify risk genes and the interpretation of genetic test results' ( $p 2$ ). In spite of these difficulties, it is likely that more genetic tests will become available, and it is important to ask whether they are likely to bring benefits. On the one hand, knowledge of the vulnerability to a certain psychiatric disorder can inform prevention and treatment. On the other hand, the very same knowledge can cause psychological harm or lead to discrimination.

Let's consider two examples of genetic testing for psychiatric disorders, depression and Alzheimer's disease. Depression is manifested in feelings of sadness experienced over a long period of time and interfering with social functioning. It can be triggered by stressful life events, illness, alcohol and drug misuse, isolation, giving birth. Depression 'runs in families': if one has a biological parent having depression, then one's chances of developing depression are threefold. Research is being done into the genetic aspects of depression, and the first tests have been proposed. Newson ${ }^{15}$ discusses the ethical implications of 5 HTT testing that has been available for some time and is used both pre-symptomatically and as an aid to diagnosis.
Laegsgaard et al $^{14}$ conducted structured interviews with a small sample of people with depression who had participated in genetic research.

Participants reported an altruistic motivation for participating ('genetic research may make no difference to me, but may impact positively on future generations'). The case of genetic testing for $\mathrm{HD}$ case showed positive attitudes towards the test before it was developed, but this did not translate into a large uptake of the test when it became available. The situation might be different in the case of depression, as Newson ${ }^{15}$ observes: 'Nearly two-thirds of Wilhelm et al.'s cohort consented to the 5HTT genetic test; a higher rate than that observed for singlegene conditions such as Huntington's disease. This result is consistent with studies that predicted high levels of interest in psychiatric genetic testing' ( $p$ 189). Some results suggest positive attitudes towards having more information in the case of depression. For instance, participants in the study by Laegsgaard et $a l^{14}$ reported that after the testing, there was greater discussion within the family and increased awareness of depression as a genuine psychiatric disorder rather than a character fault. This was useful in helping sufferers understand depression as a 'disorder', and it was also psychologically beneficial as it allowed sufferers not to feel blame or responsibility.

Less positive effects were also reported: there was increased concern about family members who were perceived as 'at risk', but had not yet fully developed the condition and might never do so (an example of the creation of a population of "worried well'). Another common attitude among those not favourable to testing was the sense that the genetic tests were useless because they could not directly contribute to treatment-which parallels general concerns about the purpose of testing. A general worry is that people may become more prone to depressions as a result of being told that they are at risk of developing depression. As Chadwick ${ }^{16}$ says, 'In the case of mental disorders, there may be additional factors associated with self-fulfilling prophecy of a predisposition to, for example, depression' ( $p$ 36). Stigma and discrimination were also discussed, and the most common result was that a better understanding of the genetic aetiology of depression could reduce the stigma associated with the condition, at least in the individual sufferer and his or her family. As one of the participants said, "Knowing that depression is a disease has helped me-but I don't see this happening in the society. To other people is still a matter of pulling oneself together" ( $p 7) .{ }^{14}$ This shows that testing can promote knowledge about a psychiatric condition and decrease stigma among those who obtain such knowledge. In the wider societal context, although, discrimination remains a danger.

Alzheimer's disease is a common form of dementia and involves impaired cognition, especially memory loss. It is degenerative, so patients worsen as time goes by until they stop functioning socially (eg, they cannot engage in conversation). Although it is commonly regarded as a disease of old age, there are also forms of early-onset Alzheimer's, which manifest at 40 or 50 years of age. ${ }^{17}$ Healthy people who have relatives afflicted by Alzheimer's disease may be genetically tested, but at the moment, it is possible only to predict the development of earlyonset versions of the disease that are caused by mutations in single genes called APP, PS1 and PS2. As there are early-onset forms of the disease that are not caused by such mutations, genetic testing may not be able to predict half of the relevant cases. For late-onset Alzheimer's, the genes responsible have not been reliably identified yet, but increased risk has been observed in the presence of the gene apolipoprotein E. Inheriting the gene does not guarantee that one will develop Alzheimer's 
disease. A blood test to detect apolipoprotein $\mathrm{E}$ is available, but at this stage it cannot be reliably used to predict an individual's risk factor. ${ }^{18} 19$

As there is no cure or effective treatment for Alzheimer's disease, it has been argued that the benefits of knowing that the disease will strike are limited. ${ }^{20}$ One possible benefit is that people who are predicted to have a higher risk of developing the disease can reduce such a risk by adopting a healthier lifestyle (eg, by taking vitamins and exercising). Another benefit consists in the possibility for forward planning, but this benefit is constrained by the uncertainty surrounding the results of the currently available testing. In a study by Roberts et al, ${ }^{21}$ people whose parents had been affected by the disease were contacted and asked whether they wanted genetic susceptibility testing. Of the people contacted, $24 \%$ opted for testing and provided a variety of reasons for their choice, from desiring to contribute to research and hoping in the future development of effective treatment to wanting to plan for longterm care. In a survey, Neumann et al ${ }^{22}$ found that a high percentage of the general population would choose to take a genuinely predictive genetic test for Alzheimer's disease (79\%), but interest would fall dramatically for a test that was only partially predictive. The main reason for wanting to know about the risk to develop the disease was, again, advance planning (eg, sign advance directives, get insurance, prepare financially). The results of this survey suggest that people do value genetic testing if the resulting information is accurate enough to allow for planning.

We saw that many of the general arguments for and against genetic testing also apply to psychiatric disorders with (partially) known genetic bases. One thing to notice is that the difficulties in tracking the aetiology of some forms of mental illness make predictive testing unreliable and thus reduce its potential benefits. Moreover, the fact that psychiatric disorders such as depression and dementia are often accompanied by stigma and discrimination can be used to support or oppose predictive testing. On the one hand, awareness of the genetic origins of some disorders reinforces the idea that abnormal behaviour is not something to be blamed for but the symptom of a disease. On the other hand, when confidentiality is not respected, knowledge that one is at high risk of developing a certain disorder can give rise to discrimination (eg, by insurance companies or employers).

Finally, in conditions such as HD and breast cancer, the rights and interests of third parties offer a reason against the right not to know as genetic information is 'shared' or 'family' information. ${ }^{23}$ Genetics shifts the focus from the individual to the group, ${ }^{24}$ and the focus of communal models of ethics is solidarity, not the protection of individual privacy. ${ }^{26}$ This line of reasoning applies to psychiatric disorders with known genetic bases, but seems far less relevant to psychiatric disorders that have no known genetic bases as family members would not be prevented from acquiring important information about themselves if the right not to know were upheld.

\section{THE RIGHT NOT TO KNOW IN PSYCHIATRIC DIAGNOSIS}

As we saw in Introduction, both those who defend and challenge the right not to know appeal to considerations about autonomy, and these seem just as relevant to psychiatric diagnosis and prognosis as to genetic testing. For instance, one could argue that the client should always be informed about her diagnosis (1) out of respect for autonomy, (2) to preserve trust in the doctor/client relationship, (3) in recognition of the reciprocal obligations of doctor and client and (4) to understand and manage her symptoms.

However, there also seem to be reasons for not telling the whole truth, particularly when the diagnosed disorder is associated with stigma, irreversibility and lack of effective treatment. Anecdotally, clinicians report that there is disagreement about whether it is appropriate to disclose a diagnosis of schizophrenia to clients, as schizophrenia is stigmatised as a chronic disorder. Initially, some clinicians prefer to talk about 'psychotic episodes', because reference to symptoms suggests that the condition is not necessarily there to stay. Clients are told nothing strictly speaking false, but only half of the truth, in order to 'protect' their self-esteem and sustain their will to recover. The idea is that knowledge of diagnosis and prognosis can make things worse for the client when the disorder is commonly stigmatised as untreatable or irreversible, and doctors should privilege the success of therapeutic interventions over other considerations. In a forthcoming paper, Rachel Cooper argues that people diagnosed with psychopathy soon realise that their condition is not easily treatable, and knowledge of their diagnosis has no positive effects on them.

Another reason to withhold information emerges in the context of disorders that impair cognitive functioning-clients may be unable to fully understand the information given to them or be motivated not to know. Non-disclosure is often the standard practice when it comes to dementia. In the available surveys, it is observed that progressively less information is given to clients who have more severe dementia. Interestingly, although relatives often prefer for the diagnosis not to be disclosed to clients, there is some evidence that most people ( $92 \%$ in the study by Erde et al $^{27}$ on Alzheimer's disease) would prefer to be told the truth. Marzanski ${ }^{28}$ interviewed 30 clients with dementia and found that almost $50 \%$ of them had good insight into their condition (eg, they knew they had serious problems with memory), but 20 had never been told about their illness by doctors or family members, although nurses and friends had passed some information onto them ( $p$ 109). Twenty-one out of 30 clients expressed a desire for more information and were especially interested in the possibility of recovery. Conversely, nine clients said they did not want any additional information about their illness, but the motivation was not always the same: some already had full insight and did not see the need for an official diagnosis and others were simply in denial.

Although it is based on a limited sample, this study shows significant personal differences in the preferences people have with respect to knowing their condition-some want the opportunity to know about their diagnosis and others prefer not to know. This study also shows that there are some similarities between information about predictive testing and information about diagnosis: the information is regarded as more valuable if it has implications for lifestyle choices or possibility for treatment.

\section{CONCLUSIONS}

There are two common threads in the current debates on the right not to know: (1) genetic information brings both benefits and costs and (2) there can be marked individual differences in the interests people have in obtaining such information and in their psychological reaction to it. As shown by the variety of attitudes towards genetic testing for depression and towards the diagnosis of dementia, some people prefer to know and other people prefer not to know, especially when no effective treatment is available. 
We considered the view that when one's diagnosis of schizophrenia or dementia can compromise the management of symptoms, there are reasons for non-disclosure. However, not all circumstances would equally support an interest in not knowing. While it might be important for some people not to know the details of their diagnosis in order for them to cooperate with healthcare professionals and family members and be treated successfully, it is difficult to justify the decision to keep a diagnosis from clients when everybody else around them knows about it. Would non-disclosure be a responsible decision made for therapeutic reasons or an instance of deception?

A preliminary conclusion, then, is that it is important to consider people's interests in knowing and not knowing when it comes to psychiatric or other disorders, but it seems inappropriate to regard such interests as the bases of 'rights' to be upheld in all the relevant circumstances.

Acknowledgements The authors acknowledge the intellectual support of the Health and Happiness Research Cluster at the University of Birmingham. The corresponding author was the recipient of a Wellcome Trust Research Expense Grant entitled 'Rationality and Sanity: Implications of a Diagnosis of Mental Illness for Autonomy as Self Governance' during the preparation of this paper.

Competing interests None.

Provenance and peer review Not commissioned; externally peer reviewed.

\section{REFERENCES}

1. Forrest $\mathbf{K}$, Simpson SA, Wilson BJ, et al. To tell or not to tell: barriers and facilitators in family communication about genetic risk. Clin Genet 2003;64:317-26.

2. Harris J, Keywood K. Ignorance, information and autonomy. Theor Med Bioeth 2001:22:415-36.

3. Malpas $\mathbf{P}$. The right to remain in ignorance about genetic information-can such a right be defended in the name of autonomy? N Z Med J 2005;118:U1611. http:// www.nzma.org.nz/journal/118-1220/1611 (accessed Mar 2011).

4. Husted J. Autonomy and a right not to know. In: Chadwick R, Levitt M, Shickle D, eds. The Right to Know and the Right not to Know. Aldershot: Ashgate, 1997:55-68.

5. Doukas DJ, Berg JW. The family covenant and genetic testing. Am J Bioeth 2001:1:2-16.

6. Parker M, Lucassen AM. Genetic information: a joint account? BMJ 2004;329:165-7.

7. Andorno R. The right not to know: an autonomy based approach. J Med Ethics 2004;30:435-9.

8. Feinberg J. The child's right to an open future. In: Curren R, ed. Philosophy of Education: An Anthology. Oxford: Blackwell, 2006:112-23.
9. Creighton S, Almqvist EW, MacGregor D, et al. Predictive, pre-natal and diagnostic genetic testing for Huntington's disease: the experience in Canada from 1987 to 2000. Clin Genet 2003:63:462-75.

10. Harper PS, Lim C, Craufurd D. Ten years of presymptomatic testing for Huntington's disease: the experience of the UK Huntington's Disease Prediction Consortium. J Med Genet 2000:37:567-71.

11. Butow PN, Lobb EA, Meiser B, et al. Psychological outcomes and risk perception after genetic testing and counselling in breast cancer: a systematic review. Med $\mathrm{J}$ Aust 2003;178:77-81.

12. Lerman C, Croyle RT, Tercyak KP, et al. Genetic testing: psychological aspects and implications. J Consult Clin Psychol 2002;70:784-97.

13. van 't Spijker A, ten Kroode HF. Psychological aspects of genetic counselling: a review of the experience with Huntington's disease. Patient Educ Couns 1997;32:33-40.

14. Laegsgaard MM, Stamp AS, Hall EO, et al. The perceived and predicted implications of psychiatric genetic knowledge among persons with multiple cases of depression in the family. Acta Psychiatr Scand 2010;122:470-80.

15. Newson AJ. Depression under stress: ethical issues in genetic testing. $\mathrm{Br} \mathrm{J}$ Psychiatry 2009;195:189-90.

16. Chadwick RF. Ethical issues in psychiatric care: geneticisation and community care. Acta Psychiatr Scand Suppl 2000;101:35-9.

17. Fogarty M. Genetic Testing for People Without Symptoms of Alzheimer's. Genetic Health, 2001. http://www.genetichealth.com/ALZ Genetics Testing in Healthy People.shtml (accessed Mar 2011)

18. National Institute of Aging. Alzheimer's Disease Genetics Fact Sheet. National Institute of Health, 2008. http://www.nia.nih.gov/Alzheimers/Publications/geneticsfs. htm (accessed Mar 2011).

19. Zick CD, Matthews CJ, Roberts JS, et al. Genetic testing for Alzheimer's disease and its impact on insurance purchasing behavior. Health Aff (Millwood) 2005;24:483-90

20. Schutte DL. Genetic testing in Alzheimer's disease. Benefits, risks and public policy J Gerontol Nurs 1998;24:17-23

21. Roberts JS, Barber M, Brown TM, et al. Who seeks genetic susceptibility testing for Alzheimer's disease? Findings from a multisite, randomized clinical trial. Genet Med 2004;6:197-203

22. Neumann PJ, Hammitt JK, Mueller $C$, et al. Public attitudes about genetic testing for Alzheimer's disease. Health Aff (Millwood) 2001;20:252-64.

23. Widdows H. Conceptualising the self in the genetic era. Health Care Anal 2007:15:5-12.

24. Brock DW. Genetics and confidentiality. Am J Bioeth 2001;1:34-5.

25. Widdows H, Mullen C. The Governance of Genetic Information: Who Decides? Cambridge: Cambridge University Press, 2009.

26. Chadwick RF. The right to know and the right not to know-ten years on. In: Rehmann-Sutter C, Müller H, eds. Disclosure Dilemmas: Ethics of Genetic Prognosis After the 'Right to Know/Right not to Know' Debate. Aldershot: Ashgate, 2009:9-18.

27. Erde EL, Nadal EC, Scholl TO. On truth telling and the diagnosis of Alzheimer's disease. J Fam Pract 1988:26:401-6.

28. Marzanski M. Would you like to know what is wrong with you? On telling the truth to patients with dementia. J Med Ethics 2000:26:108-13. 